\title{
Differentiation of the Atmospheric Moisture Collected by Dew and Fog
}

\author{
Esmaiel Malek \\ Department of Applied Aviation Science, Embry-Riddle Aeronautical University, Daytona Beach, FL 32114-390, USA
}

\begin{abstract}
Dew and fog play major roles in providing the atmospheric moisture for plants and arthropods living in arid regions all over the world. Studies are needed to discriminate between dew and fog. A radiation system was developed for measuring the incoming and outgoing solar (shortwave) radiation using two CM21 Kipp \& Zonen pyranometers (one inverted), and the incoming (atmospheric) and outgoing (terrestrial) longwave radiation using two CG1 pyrgeometers in Logan $\left(41^{\circ} 47^{\prime} \mathrm{N}, 111^{\circ} 51^{\prime} \mathrm{W}, 1^{\prime}, 460 \mathrm{~m}\right.$ above mean sea level), Utah, USA, continuously since 1995. These instruments are ventilated with heated air to prevent precipitation of dew and frost on the sensors, which otherwise would disturb the measurements. Based upon these measurements and an algorithm, the cloud base height, the cloud base temperature and percent of cloudiness can be parameterized at local scale. A cloud base height around zero would indicate fog at the local scale. In 1999, Bowen ratio system was added to measure the evapotranspiration, dew and frost continuously throughout the year at the same location close to the radiation system. Combining these two systems (radiation and Bowen ratio) has yielded a reasonable approach to differentiate between the atmospheric moistures collected by dew and fog.
\end{abstract}

Key words: Dew, fog, short and longwave radiation.

\section{Introduction}

Both dew and fog play integral roles in many diverse ecosystems. The effects of dew and fog could be beneficial or harmful. From the beneficial point of view, they could be major sources of moisture for plants and arthropods. The dew contribution to the annual water balances in semi-arid valleys in the USA was reported [1]. Also, the effects of dew, frost and snow on radiometry were evaluated [2]. The ability of desert arthropods to utilize dew, fog and damp hygroscopic material as a source of moisture in arid regions of Israel was studied [3]. On the other hand, dew and fog can have harmful effects on plants by supplying moisture for bacterial and fungal plant disease and pest development. The effects of dew on planning plant disease programs was reported [4]. The effects of dew on disease severity and latent infection caused by Cercospora kikuchii on soybeans was also studied [5].

The chief advantage of recording dew and fog lies

Corresponding author: Esmaiel Malek, Ph.D., main research filed: meteorology. in providing information on the duration of these two parameters' occurrences, which is even more important than the amount of dew and fog quantified by the instruments. Dew and fog occur most of the time during cold and nearly calm conditions when the air is saturated (a relative humidity of around 100\%). But how can these two be differentiated? No work has been done in this regard. This subject will be elaborated in this article.

\section{Instrumentations}

Radiation and Bowen ratio stations were set up in Logan $\left(41^{\circ} 47^{\prime} \mathrm{N}, 111^{\circ} 51^{\prime} \mathrm{W}, 1,460 \mathrm{~m}\right.$ above mean sea level), Utah, USA. The experimental site is far away from any obstacle and is located in the middle of a field covered mostly by cheatgrass (Bromus tectorum L.). The radiation station used two CM21 Kipp \& Zonen pyranometers (one inverted) to measure the incoming $\left(\mathrm{R}_{\mathrm{si}}\right)$ and the outgoing $\left(\mathrm{R}_{\mathrm{so}}\right)$ or reflected shortwave radiation, respectively. Also, two CG1 Kipp \& Zonen pyrgeometers (one inverted) were used to measure the incoming longwave $\left(\mathrm{R}_{\mathrm{li}}\right)$ or 
atmospheric radiation and the longwave $\left(\mathrm{R}_{\mathrm{lo}}\right)$ or terrestrial radiation, respectively. These sensors were equipped with 4 CV2 Kipp \& Zonen CVB1 ventilation systems. The ventilation air was heated at the rate of $5 \mathrm{~W}$ to prevent formation of dew and frost on the pyranometers and pyrgeometers [6]. The radiation balance equation for any site can be expressed in Eq. (1):

$$
R_{n}=R_{s i}-R_{s o}-R_{l o}+R_{l i}
$$

Where, $R_{n}$ is the net radiation. The Bowen ratio station (Campbell Scientific Inc., CSI) is about $15 \mathrm{~m}$ away from the radiation station. It measured the air temperatures and moisture at $1 \mathrm{~m}$ and $2 \mathrm{~m}$ above the ground for computing latent (LE), sensible $(\mathrm{H})$ and surface soil $\left(G_{\text {sur }}\right)$ heat fluxes of the energy balance components [7]. The energy balance equation for any site can be expressed in Eq. (2):

$$
\pm R_{n}= \pm L E \pm H \pm G_{\text {sur }}
$$

Where, all terms could be expressed as $\mathrm{W} \cdot \mathrm{m}^{-2}$. The negative $\mathrm{LE}$ is an indication of moisture deposition by dew $[1,2]$. The Vaisala HMP45C temperature and Relative Humidity (RH) probes and CS105 barometric pressure sensors (Campbell Scientific, Inc., CSI) were used at both stations to measure the air temperature $\left(\mathrm{T}_{\mathrm{a} 2}\right)$, Relative Humidity $\left(\mathrm{RH}_{2}\right)$ and pressure at $2 \mathrm{~m}$ above the ground, respectively. The wind speed and direction at $3 \mathrm{~m}$ was measured by a 05103-L RM Young Wind monitor at both stations. MSX20R solar panels were used to charge the stations' deep cycle batteries during the daytime. Also, 4,000 ZL infrared thermometers (Everest), a 385 Met One (CSI) heated rain and snow gage were used to measure the surface temperature and precipitation, respectively.

Fig. 1 shows the radiation station along with the Bowen ratio station in the background in Logan, UT, USA. Instruments are: the net radiometer (the most left-hand side on the 3-m horizontal bar), the radiation assembly (two pyranometers, one facing up and two pyrgeometers, one facing up), solar panel, wind sensor, temperature and humidity sensors and the heated rain gauge [8]. An AC power source (110 Volts) has been provided to ventilate the Kipp \& Zonen radiation system throughout the years.

Fig. 2 depicts the Bowen ratio station at the same location as in Fig. 1. Instruments are: the net radiometer (on the lower bar) and the two funnels for the measurement of air temperatures and moistures on both bars, solar panel, the wind and rain sensors and temperature and humidity sensors [2]. The white boxes at both stations contain the CR 23-X dataloggers (CSI) for recording the weather. All of the above-mentioned parameters were measured every two seconds and averaged into 20-minute intervals continuously throughout the years.

\section{Methodology}

\subsection{Evaluation of Fog}

An algorithm was developed for parameterization of cloud at local scale $[6,8]$. The approach is based on the radiation difference between cloudless and cloudy skies. Many researchers have attempted to formulate the cloudless and cloudy skies effective atmospheric emissivity based on theoretical and empirical concepts. A brief review of past work was reported by Malek, E. [9]. The cloudless-sky atmospheric emissivity $\left(\varepsilon_{a(\text { Cloudless })}\right)$ as:

$$
\varepsilon_{a(\text { Cloudless })}=R_{l i(\text { Cloudless })} / \delta^{*}\left(T_{a 2}\right)^{4}
$$

Where, $\mathrm{R}_{\mathrm{li}(\text { Cloudless) }}$ is the cloudless incoming longwave radiation in $\mathrm{W} \cdot \mathrm{m}^{-2}$ measured by pyrgeometer, $\delta=5.67 \times 10^{-8} \mathrm{~W} \cdot \mathrm{m}^{-2} \cdot \mathrm{K}^{-4}$ is the Stefan-Boltzmann constant, and $\mathrm{T}_{a 2}$ in $\mathrm{K}$ is the $2 \mathrm{~m}$ air temperature. Many researchers attempted to formulate $\varepsilon_{a(\text { Cloudless })}$ using the $2 \mathrm{~m}$ air temperature and air actual vapor pressure [10-13].

The formulas for computation of the cloudless atmospheric emissivity throughout 1999 to 2003 (1,080 observations) in Logan, UT, USA and computed the cloudless-sky atmospheric emissivity were evaluated $[6,10-13]$. Statistical analysis of the data showed that 


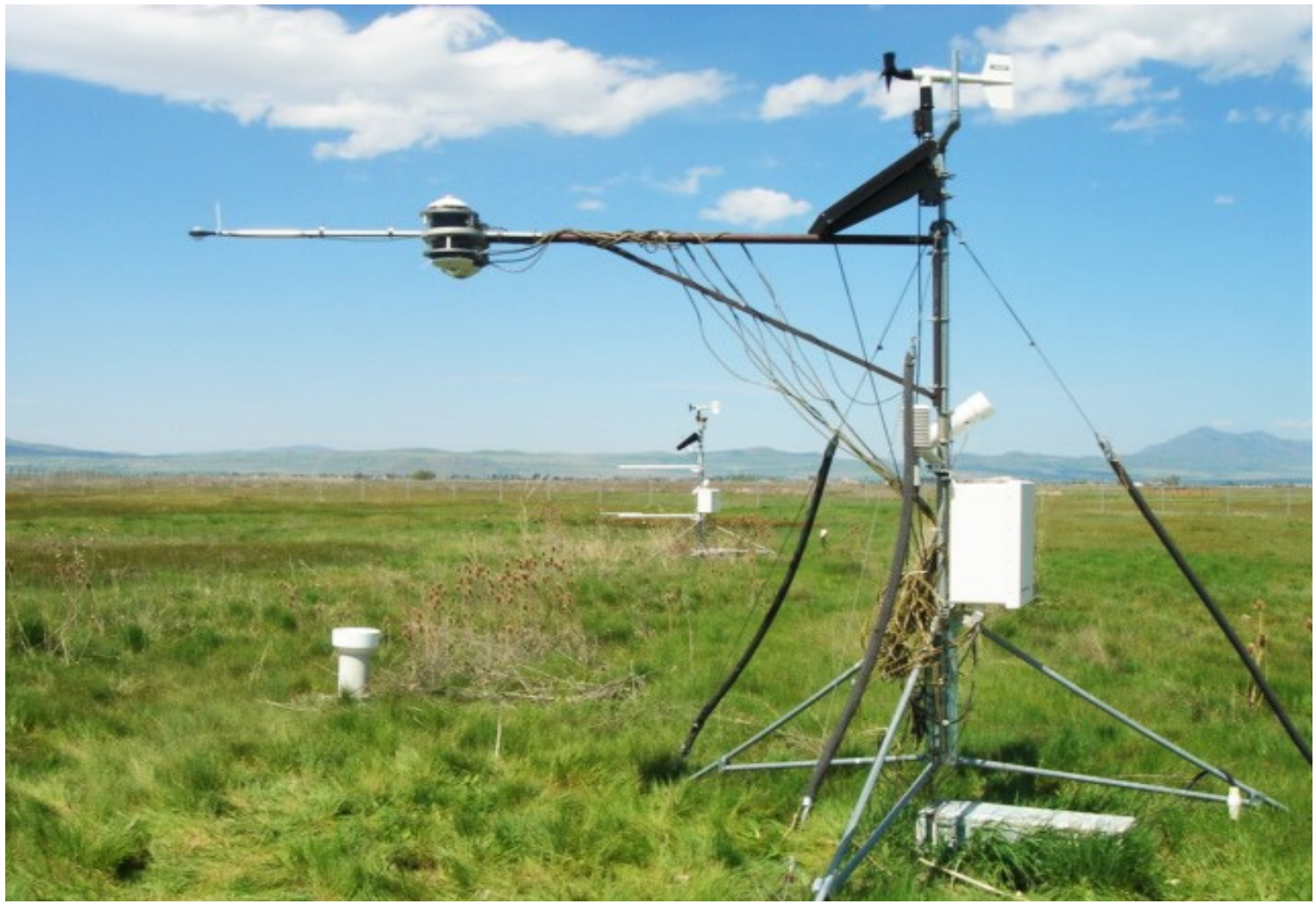

Fig. 1 The radiation and the Bowen ratio stations in Logan, UT, USA.

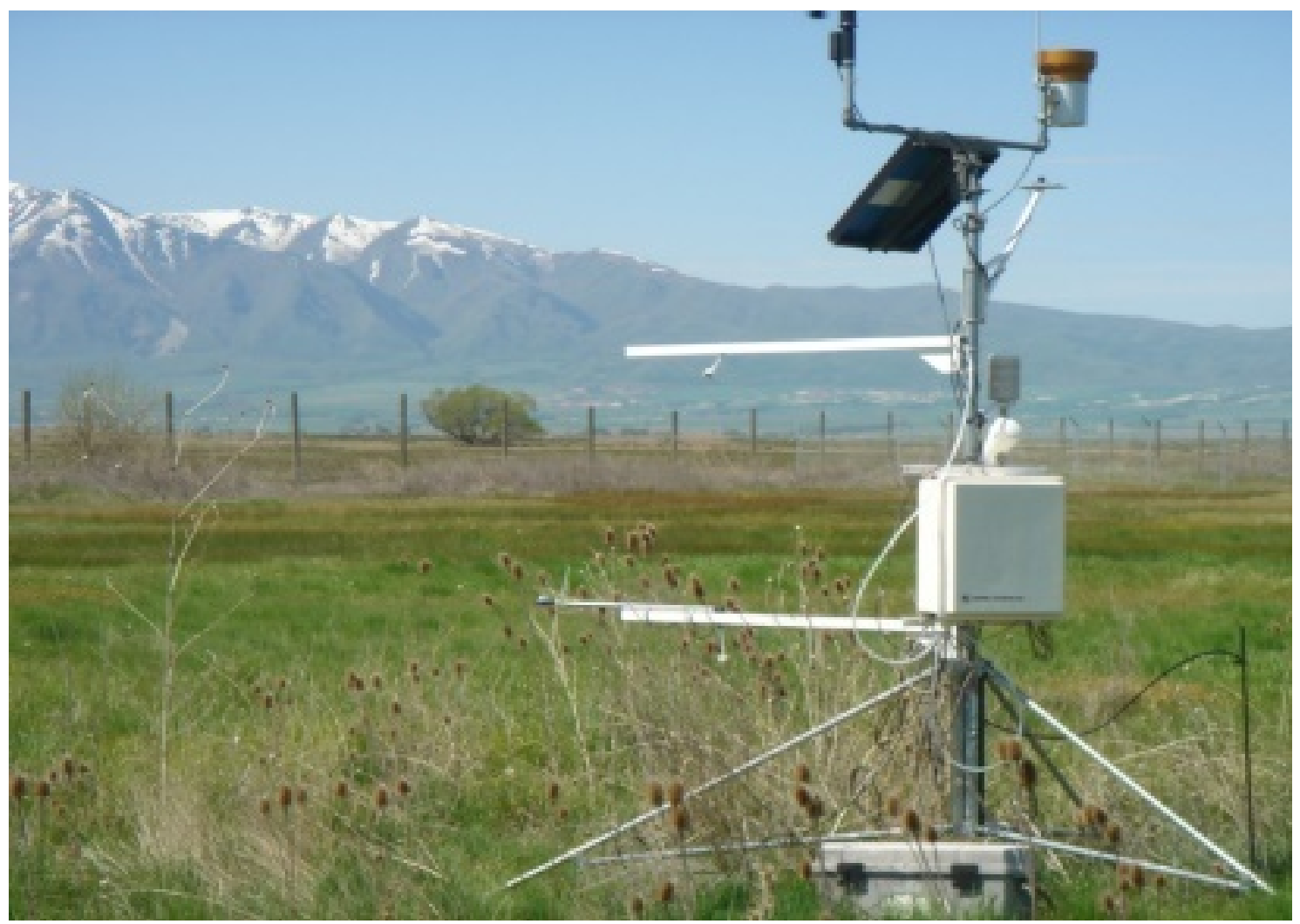

Fig. 2 The Bowen ratio station in Logan, UT, USA. 
the Idso's [12] formula had the lowest standard error of $\mathrm{Y}$ estimate, $6.10 \mathrm{~W} \cdot \mathrm{m}^{-2}$ compared with $10.37 \mathrm{~W} \cdot \mathrm{m}^{-2}$, $14.27 \mathrm{~W} \cdot \mathrm{m}^{-2}$ and $10.16 \mathrm{~W} \cdot \mathrm{m}^{-2}$ for the Brunt's [10], Brutsaert's [11] and Monteith and Unsworth's [13], respectively. The constants for the Idso's [12] formula for this work is [6]:

$$
\varepsilon_{a(\text { (Coudless })}=0.770+5.82 \times 10^{-5} E_{a 2} \times \exp \left(1500 / T_{a 2}\right)
$$

Then, the cloudless skies incoming longwave (atmospheric) radiation $\mathrm{R}_{\mathrm{li} \text { (Cloudless) }}$ can be computed as:

$$
R_{l i(\text { Cloudless })}=\varepsilon_{a(\text { Cloudless })} \times \delta \times\left(T_{a 2}\right)^{4}
$$

The presence of clouds increases the flux of atmospheric radiation received at the surface because the radiation from the water vapor and carbon dioxide in the lower atmosphere is supplemented by emission from clouds in the waveband $(8-13 \mu \mathrm{m})$, which the gaseous emission lacks.

The transmission of radiation from the layer beneath the cloud base with temperature $T_{c}$ for any sky conditions (cloudless or cloudy) is $[6,8]$ :

$$
R_{l i(\text { Total })}=\varepsilon_{a(\text { Cloudles })} \times \sigma \times\left(T_{a 2}\right)^{4}+A_{c}\left(1-\varepsilon_{a(\text { Cloudless })}\right) \sigma T_{c}^{4}
$$

Where, $\mathrm{R}_{\mathrm{li} \text { (Total) }}$ is incoming longwave radiation measured by pyrgeometer and $\mathrm{A}_{\mathrm{c}}$ (zero for cloudless sky to one for overcast sky) is the cloud amount. When the measured atmospheric radiation is greater than that of the cloudless skies, this would imply the presence of cloud in the sky. Having the temperature and moisture at the screen height ( $2 \mathrm{~m})$, and following the Poisson's equation, Normand's rule, and the thermodynamic concepts the cloud fraction, the cloud base temperature and the cloud base height can be estimated [8]. Zero height for the cloud base is an indication of fog.

\subsection{Evaluation of Dew}

Assuming similarity between the eddy diffusion coefficients for sensible (H) and latent (LE) heat fluxes, the ratio of $\mathrm{H} / \mathrm{LE}$ (the Bowen ratio, $\beta$ ) can be expressed as $[14,15]$ :

$$
\beta=C_{p} \cdot \Delta \theta /(L \cdot \Delta q)
$$

Where, $\mathrm{C}_{\mathrm{p}}=1,004 \times(1+0.90 \mathrm{q})$ in $\mathrm{J} \cdot \mathrm{kg}^{-1} \cdot \mathrm{K}^{-1}$, is specific heat of the moist air at constant pressure, $\Delta \theta$ and $\Delta q$ are the vertical gradients of potential temperature in $\mathrm{K}$ and of specific humidity in $\mathrm{kg}$ of water per $\mathrm{kg}$ of moist air, respectively, and $\mathrm{L}=$ $2,500,800-2,366.8 \mathrm{~T}$, is the latent heat of vaporization in $\mathrm{J} \cdot \mathrm{kg}^{-1}$, and $\mathrm{T}$ is in ${ }^{\circ} \mathrm{C}[8]$.

Combining Eqs. (2) and (7), the values of sensible heat $(\mathrm{H})$ and latent heat (LE, evaporation or dew) can be estimated as:

$$
H=\beta\left(R_{n}-G_{\text {surf }}\right) /(1+\beta)
$$

and

$$
L E=\left(R_{n}-G_{\text {surf }}\right) /(1+\beta)
$$

The Bowen Ratio-Energy Balance (BREB) method applied for the evaluation of evapotranspiration (+LE) and dew (-LE) throughout the year. The BREB method is a reliable approach for continuous estimation of evapotranspiration (ET, actual or potential) and dew in remote and distant areas [16].

\section{Results and Discussion}

To test the accuracy and reliability of Eq. (5) for the evaluation of cloudless skies incoming (atmospheric) radiation $\left(\mathrm{R}_{\mathrm{li} \text { (Cloudless) }}\right), \mathrm{R}_{\mathrm{li} \text { (Cloudless) }}$ with compared the measured $\mathrm{R}_{\text {lim }}$ (using the facing up pyrgeometer data) during the cloudless period of 1999-2003 with 1,080 observations in Logan, UT, USA, and the results are presented in Fig. 3. As shown in Fig. 3, there is a good agreement between the computed and measured cloudless sky atmospheric (incoming long wave) radiation with the correlation coefficient of 0.99 and standard error of $6.10 \mathrm{~W} \cdot \mathrm{m}^{-2}$.

Fig. 4 depicts the 20 min values of $2 \mathrm{~m}$ air humidity $\left(\mathrm{RH}_{2}\right)$ and temperature $\left(\mathrm{T}_{a 2}\right)$, and the surface temperature $\left(\left(\mathrm{T}_{\text {sur }}\right)\right.$ during 14-17 October, 2000 in Logan. Early morning high relative humidity during 


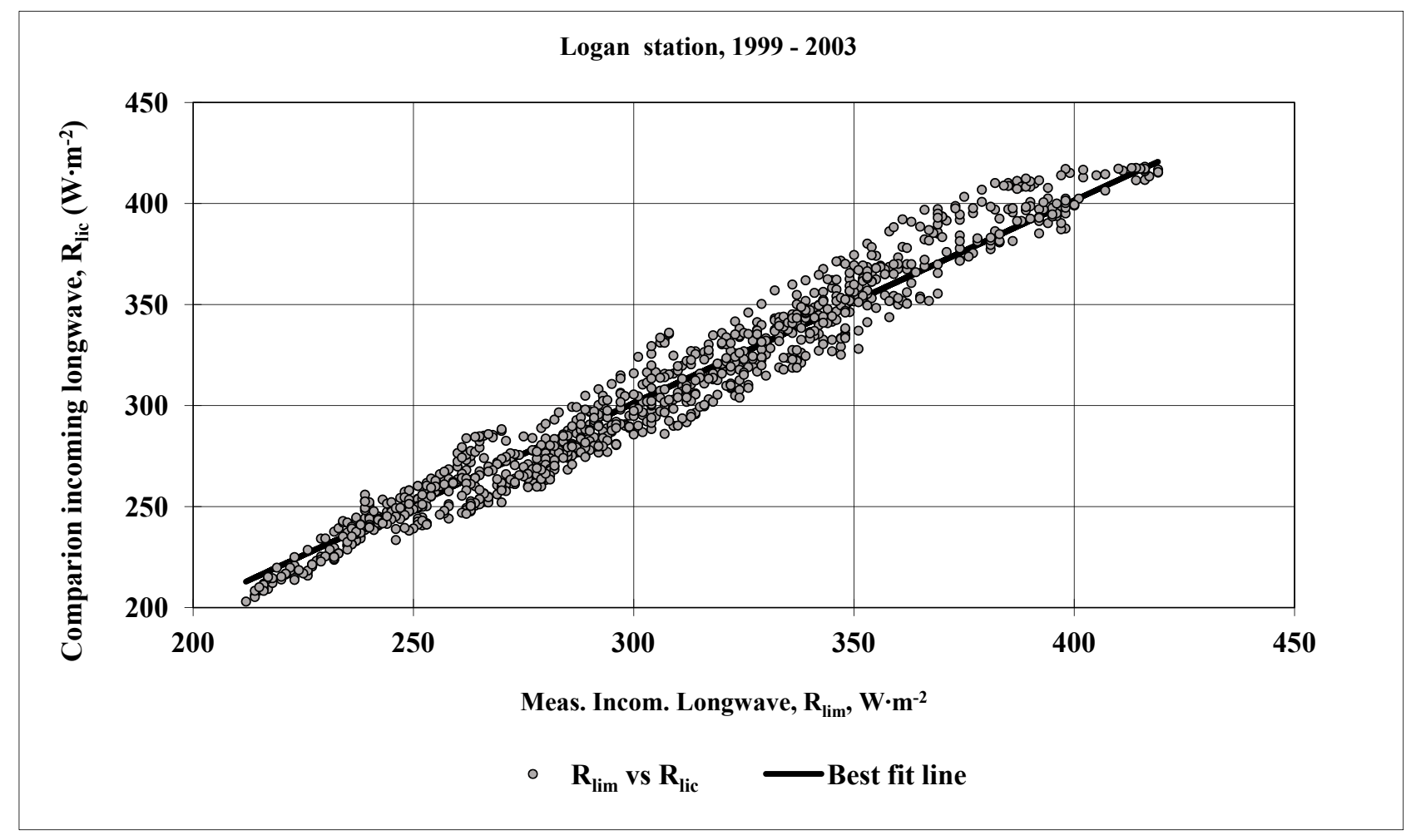

Fig. 3 Comparison of the computed $\left(R_{\text {lic }}\right)$ and measured $\left(R_{\text {lim }}\right)$ incoming longwave or atmospheric radiation, throughout the cloudless-sky periods of 1999-2003 in Logan, UT, USA.

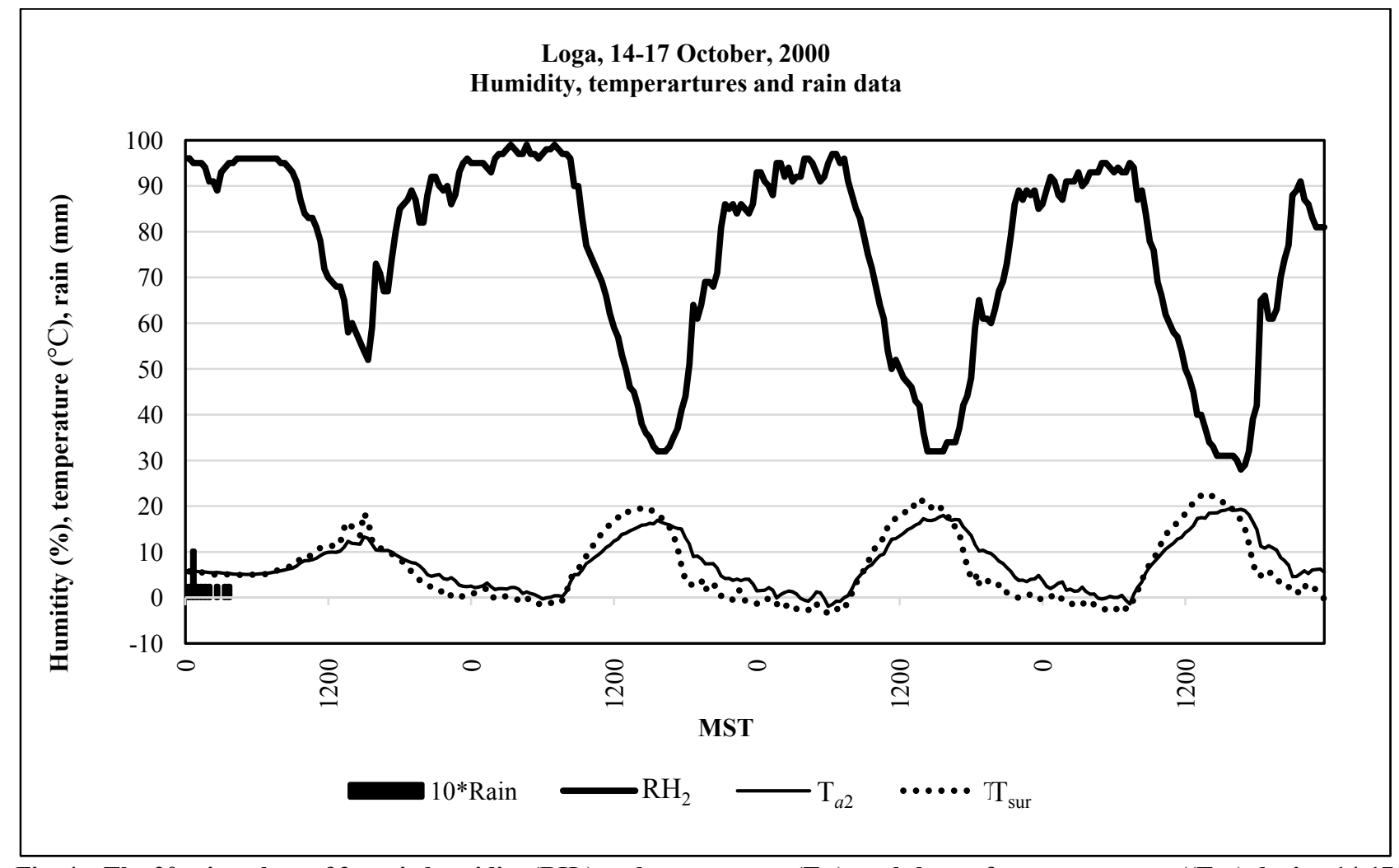

Fig. 4 The 20 min values of $2 \mathrm{~m}$ air humidity $\left(\mathrm{RH}_{2}\right)$ and temperature $\left(\mathrm{T}_{a 2}\right)$, and the surface temperature $\left(\left(\mathrm{T}_{\text {sur }}\right)\right.$ during $14-17$ October 2000 in Logan, UT. USA. 


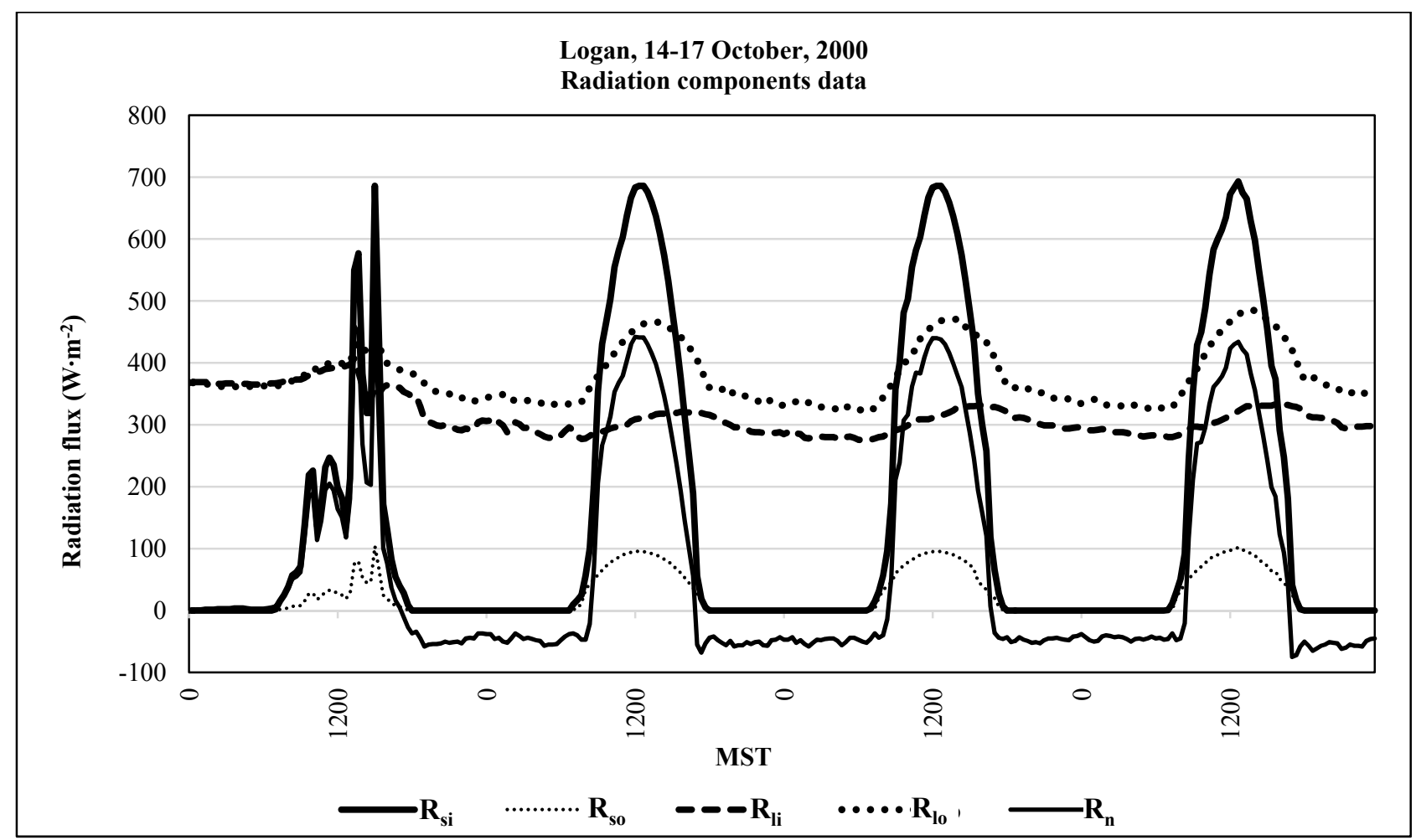

Fig. 5 The 20min values of incoming and outgoing shortwave $\left(R_{\mathrm{si}}\right.$ and $R_{\mathrm{so}}$, respectively), incoming and outgoing longwave $\left(R_{l i}\right.$ and $R_{l o}$, respectively) and net $\left(R_{n}\right)$ radiation during 14-17 October 2000 in Logan, UT, USA.

this period in Fig. 4 (except for the first rainy day) is an indication of formation of dew or fog. Fig. 5 shows the $20 \mathrm{~min}$ values of incoming and outgoing shortwave $\left(\mathrm{R}_{\mathrm{si}}\right.$ and $\mathrm{R}_{\mathrm{so}}$, respectively), incoming and outgoing longwave $\left(\mathrm{R}_{\mathrm{li}}\right.$ and $\mathrm{R}_{\mathrm{lo}}$, respectively) and net $\left(\mathrm{R}_{\mathrm{n}}\right)$ radiation during 14-17 October, 2000 in Logan, UT, USA. As shown in Fig. 5, there was an overcast sky with precipitation (rain, for this case). Also, after the passage of the rain storm, the sky was cloudless throughout the other three days (except for early mornings due to formation of low level fogs).

To evaluate the percent of sky covered by cloud and possibly fog with almost zero values for the cloud base heights during 14-17 October, 2000 period, the above-mentioned algorithm was applied [8]. Fig. 6 reveals the comparison between the measured and computed incoming longwave radiation $\mathrm{R}_{\text {lim }}$ and $\mathrm{R}_{\text {lic }}$, respectively, and percent of sky was covered by cloud and fog. As depicted in Fig. 6, $\mathrm{R}_{\mathrm{lim}}$ was much bigger than $\mathrm{R}_{\text {lic }}$ until around 7 p.m. on 14 October (overcast sky). Whenever these parameters are not identical
$\left(\mathrm{R}_{\text {lim }}>\mathrm{R}_{\text {lic }}\right)$, then cloudy skies are expected. After passing of the rain storm in the afternoon of 14 October, the cloudless skies prevailed, but due to existence of plenty of moisture in the air and colder midnight-through-early morning lower temperatures, fog formed in the following mornings after the rain.

Fig. 7 shows the cloud base height on 14 October and formation of fog in the morning during 15-17 October, 2000 in Logan. A cloud base close to zero is an indication of presence of fog. As shown in Fig. 7, there were fogs in the mornings of 15 through 17 October, 2000 at this experimental site. The nearby Bowen ratio station is unable to measure the amount water collected by fog. Instead, fog collectors (flat, rectangular nets of nylon supported by a post at either end) can be used to measure the amount of collected water [17]. During the fog-free periods, early morning dew can be evaluated by the Bowen ratio system $[1,9]$.

Fig. 8 reveals the effects of dew, frost and snow on the Q7.1 non-ventilated net radiometer on 26 April, 2004 and on 5 January, 2005, with dew in the early 


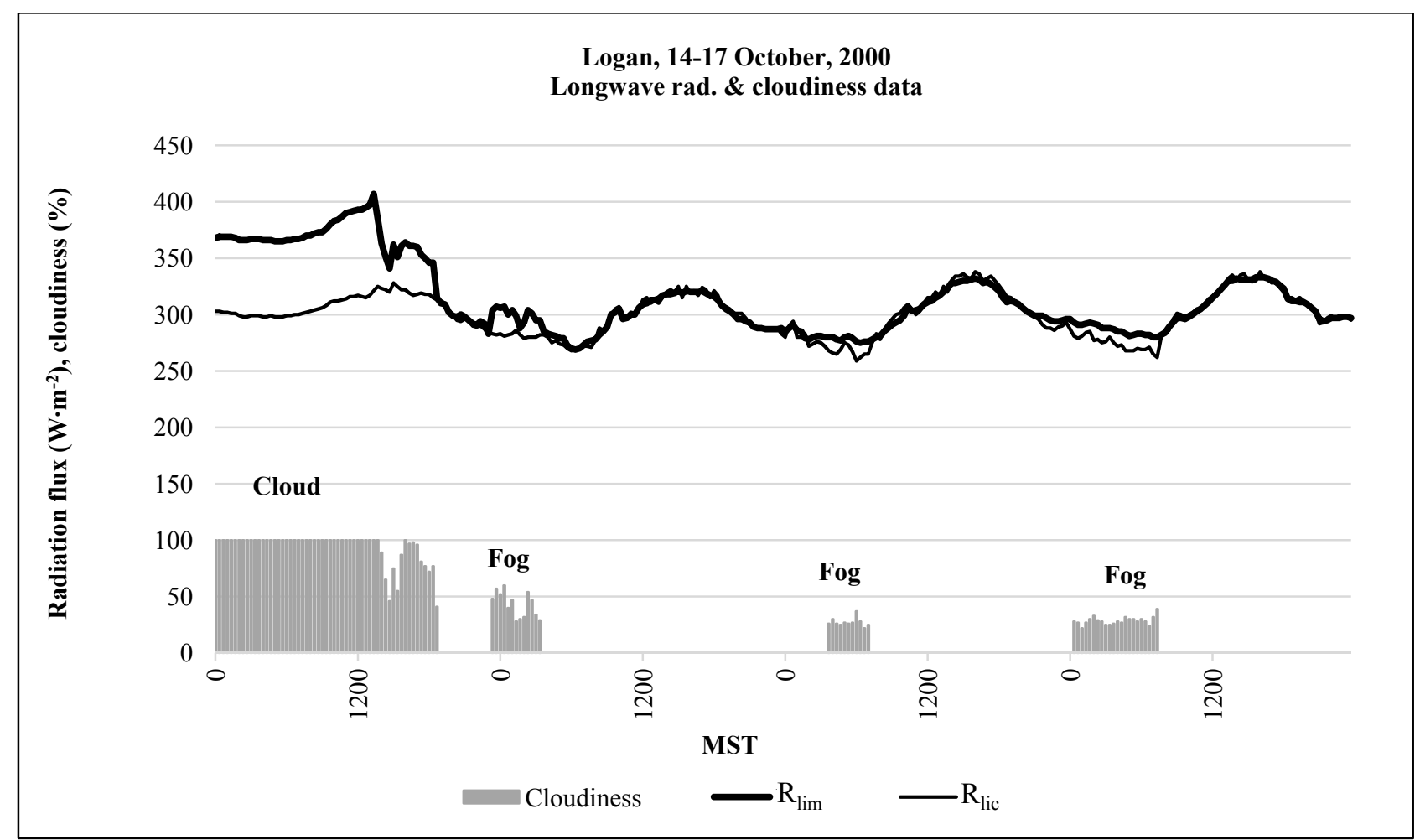

Fig. 6 Comparison between the measured and computed incoming longwave radiation, $R_{\text {lim }}$ and $R_{\text {lic }}$, respectively, and percent of sky covered by cloud and fog.

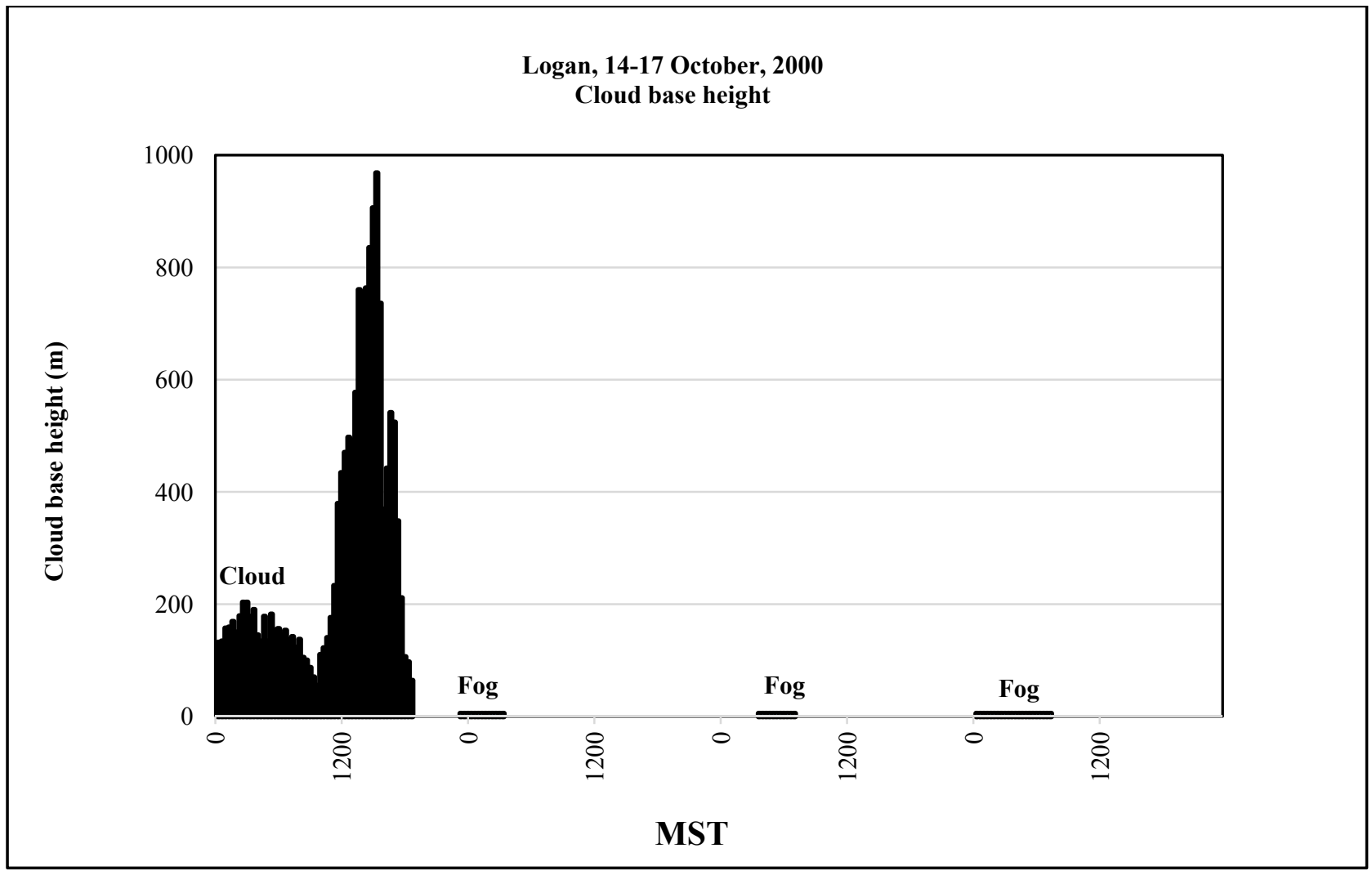

Fig. 7 The cloud base height on 14 October and formation of fog in the morning during 15-17 October 2000 in Logan, UT, USA. 


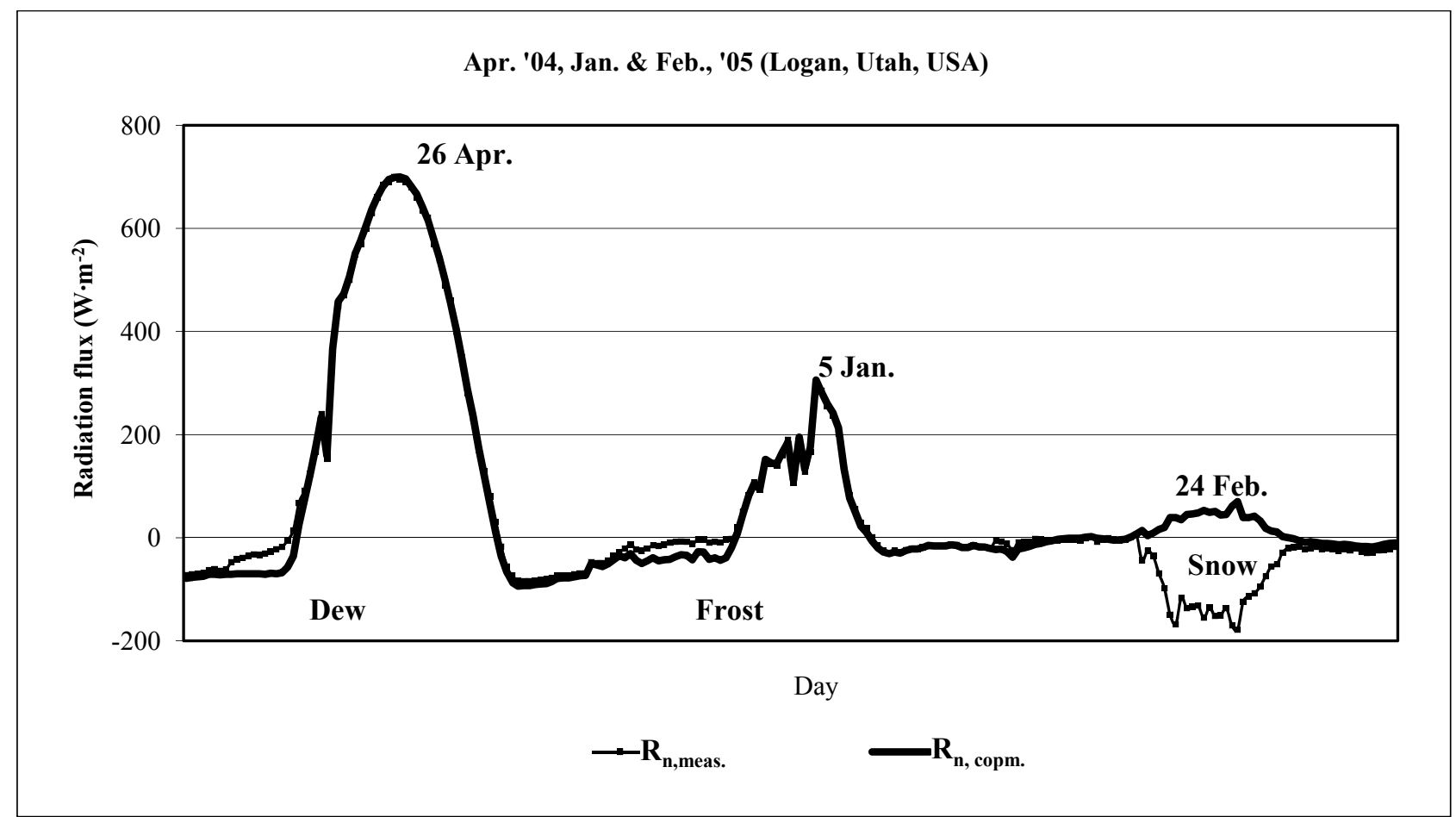

Fig. 8 Effects of dew, frost, and snow on the net radiometer on 26 April, 2004 and on 5 January, 2005, with dew in the early morning, respectively, and on 24 February, 2005, on a snowy day.

morning, respectively, and on 24 February, 2005, on a snowy day. $R_{n \text {,meas. }}$ is the flux on the non-ventilated net radiometer and $\mathrm{R}_{\mathrm{n} \text {,comp. }}$ is the flus computed by the ventilated pyranometers and pyrgeometers. The reason for higher readings by the non-ventilated net radiometer during the dew and frost periods which was due to emission of additional longwave radiation from water and ice crystals formed mainly on the upper dome thenon-ventilated net radiometer. In contrast, during the snowy day of 24 February, 2005

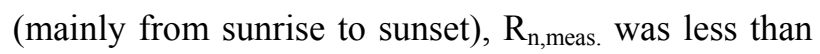
$\mathrm{R}_{\mathrm{n}, \text { comp. }}$ due to blocking of the incoming solar radiation (mainly diffuse radiation) by the upper dome of the Q7.1 net radiometer [2].

\section{Conclusions}

Comparisons between the ground-based laser beam ceilometers located at the nearby Automated Surface Observing Systems (ASOS) in the Cache Logan airport for evaluation of cloud and the proposed algorithm showed a good agreement between these two approaches [7]. This promising algorithm can be used for evaluation of cloud base temperature, cloud base height, and more importantly, the percent of sky covered by cloud at local scale. The cloud base height is a good indication of the closeness of the cloud base to the surface. Whenever this height is around zero, formation of fog is guaranteed. On the other hand, having the Bowen ratio and radiation stations close to each other, during the fog-freeperiods, dew formation can be quantified easily $[1,6]$. Fig. 8 reveals an example of effects of dew, frost and snow on radiometry.

\section{Acknowledgment}

This research was supported by Utah State University, the Utah Agricultural Experiment Station and Embry Riddle Aeronautical University. The author wishes to express his thanks to all.

\section{References}

[1] Malek, E., McCurdy, G., and Giles, B. 1999. "Dew Contribution to the Annual Water Balances in Semi-arid Desert Valleys." J. Arid Environ. 42: 71-80.

[2] Malek, E. 2008. "The Daily and Annual Effects of Dew, 
Frost, and Snow on a Non-ventilated Net Radiometer." Atmos. Res. 243-251. doi.10.1016/j.atmos.res.2008.02.006.

[3] Broza, M. 1979. "Dew, Fog and Hygroscopic Food as a Source of Water for Desert Arthropods." J. Arid Environ. 2: 43-49.

[4] Schein, R. D. 1968. "Planing a Plant Disease Program." Agroclimatol. Methods: Proc. Reading Sump. Resour. Res. 9: 141-151.

[5] Schuh, W. 1993. "Influence of Interrupted Dew Periods, Relative Humidity, and Light on Disease Severity and Latent Infections Caused by Cercospora kikuchii on Soybean." Phytopathology 83: 109-113.

[6] Malek, E. 1997. "Evaluation of Effective Atmospheric Emissivity and Parameterization of Cloud at Local Scale." Atmos. Res. 45: 41-54.

[7] Malek, E., and Bingham, G. E. 1997. "Partitioning of Radiation and Energy Balance Components in an Inhomogeneous Arid Desert Valley." J. Arid Env. 37: 193-207.

[8] Malek, E. 2015. "Comparison between the Laser Beam Ceilometer and an Algorithm for Continuous Evaluation of Cloud Base Height and Cloud Base Temperature and Cloudiness at Local Scale." GSTFJ. Aviat. Technol. 2 (1): 1-6. doi:10.5176/2382- 758 2.1.11.

[9] Malek, E. 2003. "Microclimate of a Desert Playa:
Evaluation of Annual Radiation, Energy, and Water Budgets Components." Intern. J. Climatol 23: 333-345.

[10] Brunt, D. 1932. "Notes on Radiation in the Atmosphere." Quart. J. Roy. Meteorol. Soc. 58: 389-418.

[11] Brutsaert, W. H. 1975. "On a Derivable Formula for Longwave Radiation from Clear Skies." Water Resour. Res. 11: 193-202.

[12] Idso, S. B. 1981. "A Set of Equations for Full Spectrum and 8-14 $\mu \mathrm{m}$ and 10.5-12.5 $\mu \mathrm{m}$ Thermal Radiation from Cloudless Skies." Water Resour. Res. 17: 295-304.

[13] Monteith J. L., and Unsworth, M. H. 1990. Principles of Environmental Physics. London: Edward Arnold.

[14] Bowen, I. S. 1926. "The Ratio of Heat Losses by Conduction and by Evaporation from Any Water Surface." Phys. Rev. 27: 779-787.

[15] Oke, T. R. 1987. Boundary Layer Climate, 2nd Ed. New York: Routledge.

[16] Malek, E. 1993. "Comparison of the Bowen Ratio-Energy Balance and Stability-Corrected Aerodynamic Methods for Measurement of Evapotranspiration." Theor. Appl. Climatol. 48: 167-178.

[17] Klemm, O., Schemenauer, R. S., Lummerich, A., Cereced, P., Marzol, V., and Corell, D. et al. 2012. "Fog as a Fresh-Water Resource: Overview and Perspectives." Ambio. 41 (3): 221-234. doi:10.1007/s13280-012-0247-8. 